\title{
INDISCIPLINA ESCOLAR NA PERSPECTIVA DE DOCENTES E GESTORES DE ESCOLAS ESTADUAIS DE INDAIATUBA/SP
}

Dirley Aparecido de Moura'

Elaine Prodócimo²

\section{RESUMO}

A presente pesquisa teve como tema a indisciplina escolar e como objetivo geral identificar o entendimento e de professores e direção de escolas públicas de Indaiatuba - SP sobre o assunto e como lidam com a temática e como objetivo específico comparar a compreensão dos professores de Educação Física (EF) e demais professores investigados. Foram realizadas vinte e quatro entrevistas com os professores e gestão escolar de seis escolas. Os dados mostram que há diversidade de respostas sobre o que docentes e gestores compreendem sobre a temática. Constatamos que a indisciplina não tem a atenção necessária, não há formação e programas específicos preventivos e não há uma participação conjunta de toda a comunidade escolar em discussões sobre o tema.

Palavras-chave: Indisciplina Escolar. Incivilidades. Educação Física.

1 Mestrando em Educação Física pela Universidade Estadual de Campinas (UNICAMP). Professor de Educação Física da Rede Municipal de Ensino de Indaiatuba. Indaiatuba/São Paulo, Brasil. E-mail: dirleypaco@hotmail.com

2 Doutora em Educação Física. Livre Docente da Faculdade de Educação Física da Universidade Estadual de Campinas (FEF/UNICAMP). Campinas/São Paulo, Brasil. E-mail: elaine@fef.unicamp.br 


\title{
SCHOOL INDISCIPLINE IN TEACHER AND SCHOOL MANAGEMENT PERSPECTIVE
} ON STATE SCHOOLS IN INDAIATUBA/SP

\begin{abstract}
This research goal was to analyze what do teachers and school management in public schools of Indaiatuba, São Paulo, understands about school indiscipline and how they deal with it. Semi structured interviews were conducted with eighteen teachers and six school management members of six schools. Data shows that there is a diversity of opinions on what is indiscipline. We found that the matter has not received the deserved attention; there are not studies or specific preventive programs, neither discussion about the theme with the community involved.
\end{abstract}

Keywords: School Indiscipline. Teachers. School.

\section{INDISCIPLINA ESCOLAR LA PERSPECTIVA DE DOCENTES Y GESTORES DE ESCUELAS ESTATALES DE INDAIATUBA/SP}

\section{RESUMEN}

Esta investigación tuvo como objetivo analizar: el entendimiento de profesores y gestores de escuelas públicas de Indaiatuba - SP sobre la indisciplina escolar; y de cómo lidian con esta temática. Se realizaron entrevistas semi-estructuradas con dieciocho profesores y seis miembros de la gestión escolar de seis escuelas. Los datos muestran que existe diversidad sobre lo que los docentes y gestores comprenden sobre indisciplina. Constatamos que el asunto no ha recibido la atención necesaria, no hay formación, programas específicos preventivos, ni participación conjunta de la comunidad escolar en discusiones sobre el tema.

Palabras clave: Indisciplina Escolar. Profesores. Escuela. 


\section{INTRODUÇÃO}

A indisciplina escolar é um fenômeno existente nas escolas que cria enormes dificuldades para docentes e alunos. Atrapalha sensivelmente a evolução das aulas, prejudica as relações entre os discentes e desses com os funcionários, professores e gestores; já os docentes reclamam da falta de respeito dos discentes (ZECHI, 2014) e que não conseguem lidar com a temática, prejudicando as relações interpessoais e o processo de ensino-aprendizagem.

Por esses e outros problemas decorrentes da situação, pesquisas na área são relevantes, pois, por afetar a convivência, contribui, entre outros fatores, para uma precarização do ambiente escolar influenciando a prática pedagógica, com professores com dificuldades em exercer a sua profissão (AQUINO, 1996). Diversos autores têm estudado o tema, como Garcia (2006), Aquino (1996), Vinha (2006), Tognetta (2006), La Taille (1996).

A despeito disso, o tema ainda é tratado como um tabu em muitas escolas, que evitam discussões sobre essa questão entre os educandos e os educadores.

Esse estado tem contribuído para o alto grau de incidência de transtornos psicológicos nos docentes, como ansiedade, estresse, dentre outros, levando até mesmo à chamada Síndrome de Burnout, causada por pressões e expectativas em torno desses profissionais, e que pode acarretar em afastamentos, licenças, abandono da profissão, precarização do ambiente de trabalho e adoecimento mental (ANDRADE; CARDOSO, 2012).

Também interfere na atuação docente, refletindo em mudança na didática das aulas e na maneira de enfrentamento desse entrave pedagógico (ZECHI, 2014), tal fato pode ser positivo quando metodologias cansativas e monótonas são alternadas por didáticas atrativas que se aproximam da realidade dos alunos, contextualizando com seus cotidianos

Diferentes componentes curriculares ${ }^{3}$ apresentam diferentes dinâmicas e isso pode refletir no comportamento dos alunos bem como na compreensão dos docentes sobre indisciplina escolar. O contexto da aula de EF é diferenciado das demais aulas de outras matérias, pois trabalha com o movimento por meio de jogos, danças, lutas, esportes e ginástica, sendo assim é notável que sejam aulas mais dinâmicas, em que não é possível, ou desejável, manter uma posição estática por muito tempo.

Nas aulas de EF podem ocorrer todos os casos de indisciplina escolar vistos nas outras matérias, até porque aulas de EF também ocorrem nas salas de aula, além de pátio, quadra, salas de vídeo, entre outros espaços, assim como casos específicos de indisciplina, por conta da liberdade de movimento e espaço, própria desse componente curricular. Como exemplo, o deslocar-se que, em aulas dentro de sala de outras matérias, muitas vezes, é tido como indisciplina, nas aulas de EF é esperado que se faça.

A presente pesquisa teve como objetivo geral identificar e analisar o entendimento de professores e direção de escolas públicas de Indaiatuba - SP sobre a indisciplina escolar e compreender como lidam com ela; e como objetivo específico comparar a

3 Para não confundir disciplina - atitude, e disciplina - matéria escolar, usaremos componente curricular e matéria para componente curricular. 
compreensão de indisciplina dos professores de educação física e demais professores investigados. Para isso em todas as escolas entrevistamos professores de educação física, e de outros componentes curriculares.

\section{INDISCIPLINA/DISCIPLINA}

É visível o quanto a indisciplina pode abranger um grande número de situações e também como esse conceito varia, seja individualmente, socialmente ou culturalmente. É algo muito amplo que pode ter vários significados de acordo com uma possibilidade inumerável de variáveis:

[...] O próprio conceito de indisciplina, como toda criação cultural, não é estático, uniforme, nem tampouco universal. Ele se relaciona com o conjunto de valores e expectativas que variam ao longo da história, entre as diferentes culturas e numa mesma sociedade: nas diversas classes sociais, nas diferentes instituições e até no plano individual a palavra indisciplina pode ter diferentes sentidos que dependerão das vivências de cada sujeito e do contexto em que forem aplicadas. [...] (REGO, 1996, p. 84).

Nas escolas, a questão da disciplina é algo frequente e atende ao colocado na citação acima sobre sua multiplicidade de interpretações, pois a mesma se relaciona com as perspectivas existentes em cada cultura, sociedade, contexto histórico e às próprias histórias de vida. Isso leva a um entendimento variável dos professores e alunos sobre a indisciplina escolar. Considerando a enorme abrangência, para o presente estudo, foi adotado o conceito de Garcia (2006, p. 126):

Quando pensado em contraste à noção de disciplina, esse conceito se articula a noção de ruptura e negação de esquemas norteadores e reguladores na escola. Entendemos a noção de indisciplina como relativa, fundamentalmente, a rupturas relacionadas às esferas pedagógica e normativa da escola. As expressões de indisciplina comumente refletem transgressões a parâmetros e esquemas de regulação da escola, e podem ser pensadas como formas de ruptura no contrato social subjacente às relações e intenções pedagógicas na escola, cujo eixo seria o processo de ensino-aprendizagem.

Adotamos como conceito geral de indisciplina o que foi citado acima, e, pautando-nos em Oliveira (2015) caracterizamos indisciplina em curricular, social, regimentar e passiva.

A indisciplina curricular, refere-se ao rompimento do contrato pedagógico prejudicando o desenvolvimento da aula e a aprendizagem escolar, ou seja, quando o aluno desrespeita regras interferindo negativamente na aprendizagem própria ou de seus pares (Oliveira, 2015).

A indisciplina regimentar rompe com regras para a organização do ambiente escolar, pois num ambiente complexo, como as escolas, onde circulam inúmeras e diferentes 
pessoas no dia-a-dia, são necessárias regras que possibilitem uma organização do tempo e do espaço condizente com o objetivo de aprendizagem:

A indisciplina regimentar trata das transgressões. Aborda a ruptura das regras justas e necessárias para a boa organização dos trabalhos na escola. Charlot (2002) afirma que a transgressão não é um comportamento ilegal do ponto de vista jurídico, mas contrário ao regulamento interno da instituição [...] (OLIVEIRA, 2015, p. 90).

A indisciplina passiva se caracteriza pela abstenção dos alunos em realizarem as atividades educativas propostas, bem como o desinteresse e apatia pelo desenvolvimento das aulas. Não atrapalha os demais e a própria aula, mas causa prejuízo a si próprio ao não participar do processo de ensino-aprendizagem, como exposto por Oliveira (2015, p. 90):

Caracteriza-se pela falta de motivação dos alunos, é como se não houvesse aproximação do interesse desses às propostas curriculares trabalhadas na escola, por exemplo, a recusa em participar das propostas e a desmotivação para o estudo e para realizar as atividades.

A indisciplina social ou incivilidade, acontece a todo momento nas escolas por meio do rompimento do que se espera ser uma boa conduta social, por meio de atitudes inadequadas ao local ou ao momento, por exemplo, utilização de celulares, deslocamento pela sala de aula enquanto os demais alunos estão sentados, brincadeiras, entre outros. As incivilidades são constantes e de menor gravidade, incomodam mais pela frequência e pelas expectativas sociais de comportamentos:

Já a indisciplina social, caracteriza-se pela incivilidade, ou seja, à ruptura das regras sociais, do que é esperado de uma "boa educação". Falta de polidez ou ações que ferem os códigos de boas maneiras. Esse problema de convivência não contradiz nem a lei e nem o regulamento interno, ela contradiz as regras de boa convivência: palavras ofensivas, grosserias, empurrões, desordem (CHARLOT, 2002). Trata-se de atentados cotidianos e recorrentes ao direito de cada um ser respeitado, ou de pequenas infrações à ordem estabelecida, diferenciando-se de condutas criminosas ou delinquentes. Incomodam mais pela intensidade e frequência do que pela gravidade. (OLIVEIRA, 2015, p. 89-90).

A partir das definições adotadas buscamos no presente estudo verificar qual é a concepção de indisciplina de professores e gestores de escolas de Indaiatuba.

\section{METODOLOGIA}

Trata-se de pesquisa qualitativa descritiva exploratória e como tal, como aponta Minayo (2009, p. 21): 
[...] Trabalha com o universo dos significados, dos motivos, das aspirações, das crenças, dos valores e das atitudes. [...] O universo da produção humana que pode ser resumido no mundo das relações, das representações e da intencionalidade e é objeto da pesquisa qualitativa dificilmente pode ser traduzido em números e indicadores quantitativos.

Para a realização do presente estudo foi utilizada entrevista semiestruturada. Sobre as mesmas, procuramos nos atentar para o exposto por Minayo (2009, p. 64):

As entrevistas podem ser consideradas conversas com finalidade e se caracterizam pela sua forma de organização. Podem ser classificadas em: [...] (b) semiestruturada, que combina perguntas fechadas e abertas, em que o entrevistado tem a possibilidade de discorrer sobre o tema em questão sem se prender à indagação formulada (grifos da autora).

\section{Levantamento de informações}

Fizeram parte do estudo seis escolas de um universo de vinte instituições estaduais de Indaiatuba/SP, segundo a Diretoria de Ensino da Região de Capivari (2015) ${ }^{4}$. Foi utilizado o critério de saturação dos dados, para o encerramento do levantamento das informações.

Foram realizadas entrevistas semiestruturadas com os professores de EF e professores de mais duas matérias em cada escola, escolhidos aleatoriamente, por meio de sorteio, e com um membro da gestão escolar, totalizando vinte e quatro entrevistas.

Foram realizadas individualmente, com o uso de gravação de áudio, na própria escola em ambiente com pouco barulho garantindo a qualidade da gravação. As entrevistas com a gestão escolar foram realizadas com os membros responsáveis por atuar com a indisciplina escolar, podendo ser coordenadoras, vice-diretoras delegadas e diretoras. As entrevistas foram transcritas de maneira literal, corrigindo apenas eventuais erros gramaticais e termos impróprios. Foi entregue termo de consentimento aos professores e aos gestores para realização das entrevistas. Os nomes dos sujeitos participantes foram mantidos em sigilo. A presente pesquisa foi aprovada pelo CEP da Universidade, por meio do Parecer: 794.093 e CAAE: 32175514.8.0000.5404.

Foi seguido o seguinte roteiro:

Roteiro - Entrevista com os Professores

- O que entende por indisciplina? Dê algum exemplo.

- Que casos de indisciplina encontra em suas aulas?

- Como trabalha com a indisciplina nas suas aulas?

- Outra informação que julgar necessária. 
Roteiro - Entrevista com a Equipe Gestora

- O que entende por indisciplina? Dê algum exemplo.

- Como a escola trabalha com os alunos tidos como indisciplinados?

- Outra informação que julgar necessária.

\section{RESULTADOS E DISCUSSÃO}

As respostas obtidas nas entrevistas foram separadas entre as que procuraram conceituar e exemplificar a indisciplina e aquelas em que foram apenas citados exemplos de indisciplina escolar, e que constituíram-se em minoria.

Entre as conceituações obtidas, destacamos primeiramente, a que entende a indisciplina como o desrespeito às regras após um consenso entre professores, alunos e equipe gestora. Como exemplificação apresentamos a posição de uma vice-diretora:

(ENTREVISTA COM A VICE-DIRETORA - ESCOLA B): Olha, a indisciplina, a gente vê assim algo que foge de uma regra, que está ali pré-estabelecida, determinada, depois de um consenso com o todo, então existe um consenso entre professores, alunos, equipe gestora para definir o que é disciplina, e quando sai disso, desse consenso, a gente entende que seja uma indisciplina [...]

Para haver o consenso mencionado pela gestora é necessário, por parte da escola, a adoção de uma discussão democrática sobre as regras e seus princípios, para que as mesmas sejam conhecidas e internalizadas por todos, havendo assim uma coerência entre todos os segmentos da escola em relação às normativas vigentes.

A construção conjunta das regras enfatizando os seus princípios contribui para a formação da autonomia dos alunos, como enfatizam Vinha e Tognetta (2006, p. 14):

Em muitas escolas, ao mesmo tempo em que se discursa sobre a autonomia e respeito, ensina-se na prática que o certo é obedecer, não questionar, submeter-se. [...] A escola tem que construir um ambiente propício para que a criança experiencie situações que a levem a construir seus valores morais, situações de respeito mútuo [...]

Quando não ocorre uma discussão democrática sobre as regras da escola e seus princípios, muitos discentes não compreendem os seus significados e acabam se rebelando contra as mesmas, como afirma La Taille (1996), para quem a indisciplina pode ser uma forma de revolta contra as normas, ou o seu desconhecimento. Um docente de português da Escola E cita casos pertinentes sobre isso, que encontra em suas aulas:

[...] o desdém, que é o que mais ocorre, o aluno dorme de propósito na aula, o aluno às vezes fala alto para atrapalhar a aula, faz pergunta que não é pertinente à aula, o desdém eu acho que é o que mais acontece [...]. 
Vemos um exemplo alarmante, em que o aluno, na perspectiva do professor, age de uma forma que, propositadamente, confronta a própria organização do espaço e tempo da aula, influenciando negativamente no desenvolvimento do processo de ensino e aprendizagem.

Esse confronto entre docentes e alunos poderia ser minimizado, caso houvesse uma gestão democrática em relação ao ensino, aos conteúdos, às regras e à própria metodologia das aulas com participação efetiva de todos os envolvidos. Essa resistência dos alunos fica evidente nos estudos de Aquino (1996, p. 53): “Anteriormente, disciplina evocava silenciamento, obediência, resignação. Agora, pode significar movimento, força afirmativa, vontade de transpor os obstáculos".

As escolas passaram por mudanças acompanhando os diferentes contextos históricos, inclusive no que diz respeito à forma de colocação e seguimento de regras. Ao procurar obediência cega e silêncio em relação às regras é possível que se encontre resistência, pois a nova ordem social implica em características maiores de mobilidade. Em outros tempos as escolas eram frequentadas por pessoas oriundas de uma mesma classe social, com características muito semelhantes, excluindo muitos do direito à educação, felizmente na atualidade a heterogeneidade dos alunos é imensa, minimizando em grande parte o problema da exclusão, mas necessitando de outras didáticas para lidar com as diferenças.

Por sua vez, outros entrevistados, em menor quantidade, trazem a questão da indisciplina regimentar proposta por Oliveira (2015), que transgride as regras das escolas necessárias para a boa organização do trabalho e do ambiente escolar:

(ENTREVISTA COM A COORDENAÇÃO PEDAGÓGICA - ESCOLA A): [...] quando ele não segue a essas regras, esse contrato, então nós achamos que ele está tendo algum caso de indisciplina [...] (ENTREVISTA COM A DIRETORA - ESCOLA D): A indisciplina seria comportamentos dos alunos que fogem às regras da escola [...].

Outro ponto mencionado nas respostas sobre o conceito trata-se, principalmente, da indisciplina curricular em situação de atrapalhar a progressão da aula:

(ENTREVISTA COM O PROFESSOR DE EDUCAÇÃO FÍSICA - ESCOLA B): A indisciplina seria o aluno incomodar a aula. Ele atrapalhar a progressão da aula, a aula não consegue avançar por conta da indisciplina, alguma atitude que não convém com a sala de aula, então, a princípio eu entendo indisciplina assim [...].

Na resposta apontada, o docente conceitua o que entende por indisciplina escolar colocando o foco na aula por meio de atitudes que interfiram negativamente na sua evolução. Outros sujeitos também responderam de forma similar, referindo-se a indisciplina como atitudes que atrapalham a aula, violam o direito de quem quer aprender e ensinar, interferem no desenvolvimento da turma.

Outro aspecto mencionado nas entrevistas foi a indisciplina escolar como a falta de respeito, algo que foge do padrão da aula, comportamentos inadequados ao ambiente 
escolar, fatos que são considerados como a indisciplina social, por meio das incivilidades relatada por Oliveira (2015), como é possível verificar nos excertos:

(ENTREVISTA COM A PROFESSORA DE MATEMÁTICA - ESCOLA C): Eu acho que indisciplina é a falta de respeito do aluno com os colegas e com o próprio professor. (ENTREVISTA COM A PROFESSORA DE EDUCAÇÃO FÍSICA - ESCOLA C): EU acho que a indisciplina é você não respeitar o professor [...] (ENTREVISTA COM A PROFESSORA DE PORTUGUÊS - ESCOLA F): [...] não respeita o professor, eu entendo como indisciplina.

Um menor número de entrevistados citou a indisciplina passiva, proposta por Oliveira (2015), na qual os alunos se abstêm da participação na realização de atividades pedagógicas, como mostramos abaixo:

(ENTREVISTA COM A PROFESSORA DE EDUCAÇÃO FÍSICA - ESCOLA C): não fazer as atividades propostas durante a aula [...] (ENTREVISTA COM A COORDENADORA PEDAGÓGICA - ESCOLA E): Indisciplina a gente entende que o aluno não quer participar das atividades pedagógicas, o aluno não tem um foco de aprendizagem e ele acaba falando muito, desnecessário, em momento inadequado e não participa das atividades pedagógicas e acaba tumultuando um pouco as aulas.

Outras menções esporádicas referem-se ao planejamento docente, à questão familiar, à distância do significado das aulas para os docentes e os alunos:

(ENTREVISTA COM A VICE-DIRETORA - ESCOLA C): A indisciplina no geral nessa escola, ela tem alguns problemas, ou ela está relacionada com um problema social do aluno, geralmente toda vez que a gente chama o responsável de aluno que está dando problema aqui, ele tem algum problema social dentro da família, passando por alguma dificuldade. Ou, às vezes, a indisciplina também é gerada por uma aula não preparada, o professor que vem com uma aula sem preparo, ele percebe quando o professor também não tem o controle do seu conteúdo, isso gera indisciplina [...] (ENTREVISTA COM A PROFESSORA DE EDUCAÇÃO FÍSICA - ESCOLA E): Eu acho que a indisciplina está muito ligada na distância do significado da aula para o aluno e da expectativa que o professor espera de uma sala de aula [...].

Quando os docentes e gestores escolares creditam a casualidade da indisciplina, unicamente aos familiares, aos alunos ou aos docentes, estão empobrecendo uma discussão que deve levar em conta essas vertentes pedagógicas e outras, como planejamento e metodologia de aulas, significado dos conteúdos, formulação de políticas públicas, entre outros aspectos, como Aquino, (1996, p 48-49) afirma:

Ora, não é possível assumir que a indisciplina se refira ao aluno exclusivamente, tratando-se de um problema de cunho psicológico/moral. Também não é possível creditá-la totalmente à estruturação escolar e suas circunstâncias sócio-históricas. Muito menos atribuir a responsabilidade às ações do professor, tornando-a um problema de cunho essencialmente didático-pedagógico. A nosso ver, a indisciplina 
configura como um fenômeno transversal a estas unidades conceituais (professor/ aluno/escola) quando tomadas isoladamente como recortes do pensamento. Ou melhor, indisciplina é mais um dos efeitos do entre pedagógico, mais uma das vicissitudes da relação professor-aluno [...] (grifo do autor)

Em seguida trazemos alguns casos de indisciplina que os gestores e os professores relataram que ocorrem em suas aulas.

Apesar dos professores dificilmente citarem ou conceituarem as quatro formas de indisciplina trazidas por nós na revisão, na somatória dos discursos aparecem todas elas:

(ENTREVISTA COM A PROFESSORA DE HISTÓRIA - ESCOLA A): Indisciplina nas minhas aulas, é mais a questão de eles falarem muito entre eles mesmo, ou até se xingam entre eles, dependendo do assunto que estão falando e a questão do celular, que é uma coisa bem grave. (ENTREVISTA COM A PROFESSORA DE PORTUGUÊS - ESCOLA C): [...] mas assim eu vejo muitos momentos assim que o aluno, ele não fica atento em fazer a sua atividade, ele se dispersa, ele fica apático e isso é o que eu percebo. No dia-a-dia essa questão de indisciplina, para mim é isso. (ENTREVISTA COM A PROFESSORA DE INGLÊS - ESCOLA D): Falta de respeito, não só com o professor, mas também com alguns colegas de classe. (ENTREVISTA COM O PROFESSOR DE EF - ESCOLA D): Olha, indisciplina em si, o $9^{\circ}$ ano 04, por exemplo, é uma sala muito falante, tudo para eles é motivo de chacota, então é uma sala que você tem que estar mais preparado, digamos assim, trazer a aula na ponta, na ponta da língua, saber o que você vai falar com eles [...].

Portanto encontramos nas entrevistas que ocorrem as quatro formas de indisciplina trazidas por nós na revisão: regimentar, social, curricular e passiva propostas por Oliveira (2015).

Entretanto notamos que poucos professores e gestores reconheceram todas essas características do fenômeno, sendo que o foco principal deu-se mais na conceituação geral de Garcia (2006). Foi possível perceber entre as entrevistas que poucas pessoas responsáveis pela educação reconhecem a multiplicidade do fenômeno e isso pode ser um entrave no entendimento e tratamento dessas questões nas escolas, por exemplo, se um aluno está dormindo e agindo segundo o caracterizado como indisciplina passiva, a forma de lidar é diferente de um aluno que está gritando na sala de aula, mas ambos os casos interferem nas aulas e na metodologia docente.

É necessário que toda a comunidade escolar reconheça essas formas de indisciplina e saiba diferenciar quando são apenas incivilidades que não rompem com o contrato pedagógico por meio da indisciplina social; quando se trata de algo que não prejudica a aprendizagem, mas desrespeita as normas e os combinados ocorridos durante o ano por meio da indisciplina regimentar; quando se trata de abstenção dos alunos em participarem das aulas por meio da indisciplina passiva; e quando chega a um ato que prejudica a aprendizagem dos alunos por meio da indisciplina curricular e por último quando ultrapassa a questão da indisciplina e chega à violência, para que possam lidar com essas diferentes formas de maneiras adequadas a cada uma delas. 
A visão dos professores e gestores, como vimos, sobre a indisciplina escolar, apresenta como principais atos: desrespeitar às normas, atrapalhar o desenvolvimento da aula, não realizar de atividades, conversar, usar aparelhos eletrônicos, discutir com o professor e fazer algo que foge do padrão da aula, fatos encontrados nos estudos de Conceição (2013, p. 22):

[...] Obtiveram-se os seguintes resultados: na visão dos professores $(42,86 \%)$ indisciplina é a "desobediência a regras impostas pela escola", e ainda a falta de respeito com o professor (28,57\%) e o "mau comportamento" (28,57\%). [...] Para os gestores $(50 \%)$ o "mau comportamento" seria o maior causador de indisciplina em sala de aula, seguido da "desobediência as (sic) regras escolares" (25\%) e a "falta de respeito com o professor" (25\%) no ambiente educativo.

Há uma confusão no senso comum entre indisciplina violência escolar, afinal indisciplina é violência? Violência é indisciplina? Há semelhanças, diferenças? Frequentemente constatamos essas confusões também nas escolas, sobre isso é interessante o que a vice-diretora da Escola B citou, colocando a violência, não como uma forma de indisciplina, mas como algo que vai além dela:

[...] e tem uma aluna na sala que é um caso à parte, que é a Brigite, que já ultrapassa a barreira da indisciplina, ao meu ver, ela já é uma aluna com quadro de violência, uma aluna agressiva, uma aluna que ela não é de falar muito, ela, assim, é um tanto quieta, porém é muito agressiva, então já passa, ao meu ver, ela é uma aluna violenta, apesar de aparentar sossegada, mas é uma aluna que se você se dirige a ela, questiona alguma coisa, ela já age com violência.

Essa confusão entre indisciplina e violência escolares foi evidenciada no estudo de Krawczun e Platt (2015, p. 499), que nos mostra como os atos de diferentes formas são designados como violência escolar:

É perceptível, por meio desse depoimento, a confusão dos atos que se misturam na rotina escolar. A desobediência ao comando do docente passa a ser considerada como um ato de violência, misturando-se concomitantemente com os atos realmente constituintes da violência, como por exemplo, dano ao patrimônio, agressões de ordem física e verbal.

A violência escolar se diferencia de outros casos de indisciplina escolar, embora um ato violento também seja indisciplinar, pelo motivo de rompimento às regras de boa convivência, porém nem toda indisciplina é violência. O que caracteriza que um ato indisciplinar também seja violento é a intenção de causar dano, física ou psicologicamente, à integridade do outro.

Nessa perspectiva, quando um aluno deixa de fazer lição, ele causa mal apenas a si próprio, não ferindo a integridade de outros alunos, docentes, gestores ou funcionários, já quando o discente ofende o professor com palavras de baixo calão, agride fisicamente 
outro aluno, ou comete outra atitude semelhante, o mesmo está cometendo um ato indisciplinar, pois está rompendo com regras de convivência, bem como está agindo de forma violenta, pois está ferindo a integridade do próximo.

Vemos, na visão da direção escolar apontada acima, um avanço, pois a mesma coloca a violência como algo que vai além da indisciplina.

Outro fato que merece destaque é que as respostas de professores de diferentes componentes curriculares sobre o que compreendem por indisciplina foram semelhantes. Houve poucas situações narradas que ocorrem nas aulas de educação física e não ocorrem nas demais aulas, como exposto abaixo:

(ENTREVISTA COM O PROFESSOR DE EF - ESCOLA B): Na EF a gente tem na quadra, na questão dentro das atividades, o aluno que para atingir o objetivo do jogo, [...] ele comete falta, infrações durante o jogo, [...] mesmo fazendo atividade, agora tem outros casos mais grosseiros [...] querendo pular o muro, [...] ele quer pular o muro, para ir embora, ou ele de repente não quer participar da aula e em algumas situações que eu já observei, ele pega a bicicleta dele [...] e fica andando na quadra com a bicicleta, não quer participar da aula, ou quer ficar sentado lá, mexendo com os outros alunos, [...] (ENTREVISTA COM A PROFESSORA DE EF - ESCOLA C): [...] na minha aula de educação física, eu considero indisciplina os alunos que não querem fazer as atividades propostas, ele quer ficar sentado, tem alguns casos que ele só fica sentado a aula inteira, e eu não consigo resolver esse problema.

Percebemos nesses exemplos citados que ocorrem alguns casos de indisciplina próprios da educação física, no entanto a intenção é a mesma de não fazer a atividade, mas a diferença é que na educação física não fazer atividade significa ficar sentado e na sala de aula significa, muitas vezes, ficar em movimento. E temos também a questão do jogo em si que permite outra forma de interação que em geral ocorre nessas aulas e no recreio, como atividades que visam atingir o objetivo de determinado jogo, muitas vezes atuando em equipes com uma ampla movimentação e articulação que difere das aulas em sala de aula.

Outra coisa que percebemos e que coincide com o exposto por Rego (1996) é que o conceito de indisciplina varia bastante dependendo da instituição, do contexto histórico, da cultura, das experiências e vivências individuais. Sendo assim é aceitável que encontremos uma diversidade de respostas sobre o que seria indisciplina para os docentes de diferentes escolas, ou até mesmo dentro de um mesmo colégio. É notório pelas respostas obtidas, que um fato incomoda mais um professor do que o outro e, assim sendo, o que é indisciplina para um não é para o outro e vice-e-versa.

Com relação às formas como as escolas lidam com o fenômeno da indisciplina escolar obtivemos alguns dados que merecem destaque. A principal forma mencionada pelos sujeitos foi a prescrição de regras. Também foi citada a imposição de contratos pedagógicos, projetos políticos pedagógicos e outros documentos, porém foi possível verificar que, em muitos casos, sem uma discussão democrática sobre os mesmos previamente ocorrida: 
(ENTREVISTA COM A COORDENAÇÃO PEDAGÓGICA - ESCOLA A): A indisciplina na realidade aqui na escola, nós entendemos quando o aluno não segue as regras estipuladas e os contratos pedagógicos que a escola, no início do ano, disponibiliza. Então todo ano inicialmente nós passamos nas salas, nós passamos o contrato pedagógico para os alunos [...]. (Grifo nosso).

Também destacamos a questão de as regras serem apresentadas e compreendidas de maneiras diferentes pelos discentes e docentes. Muitas vezes essas normas já estão prontas na escola e são impostas. Em alguns casos há um desconhecimento das mesmas e suas necessidades por parte de toda a comunidade escolar e em especial os alunos que não entendem o motivo para tantas regulamentações que muitas vezes se apresentam com excesso de proibições.

Para a formação humana, autônoma e cidadã é necessário ampliar os espaços de discussão democrática, em que todos os segmentos das escolas possam participar da elaboração e implantação de documentos e projetos, opinando, trazendo o seu ponto de vista e se sentindo integrante da instituição, assim criaremos um sentimento de pertencimento e envolvimento escolar, bem como tornará um ambiente mais aberto e consequentemente mais agradável e prazeroso. É importante também que haja projetos, cursos, formação continuada de todos os segmentos da escola para que possamos lidar com esse fenômeno e outros que surgem nas instituições, como notamos nos estudos de Grigolon et. al. (2013, p. 122):

É preciso que todos os envolvidos com o sistema educacional percebam-se não apenas como responsáveis pelo aprendizado de conteúdos científicos e acadêmicos, mas também pela melhoria do trabalho, discutindo regras e limites, visto que esses fatores têm constituído, em nossa sociedade contemporânea, um problema que já ultrapassou os limites da escola e se configura como uma de nossas grandes angústias sociais.

Zechi (2014, p.249) também pôde verificar que há uma ausência de projetos eficazes para a amenização de problemas de indisciplina e violência:

[...] As ações realizadas pelas escolas pesquisadas revelam uma carência de projetos que poderiam ser considerados como experiências positivas de Educação em Valores e de redução da violência e da indisciplina escolar. [...].

Nesse estudo de Zechi (2014) notamos que as escolas, os docentes e os gestores possuem boa vontade e propõem muitos projetos para atuar com a questão da indisciplina, da violência e dos valores, como notamos no nosso estudo, por exemplo, a professora de português da Escola A que relatou que montou no ano de 2014 um "Projeto Valores" e a professora de história na escola F afirmou que a escola possui também um "Projeto Valores". Contudo são ações pontuais e falta uma compreensão por parte de toda a comunidade escolar da maneira correta de desenvolver tais projetos. 
A maioria dessas experiências não promove uma verdadeira formação para a autonomia, por inúmeros motivos, como a falta de formação, projetos descontínuos, projetos intervencionistas e não preventivos, como encontramos em Zechi (2014, p. 254-255):

\begin{abstract}
Faltam estratégias claras e sistematizadas, resultando em procedimentos pontuais e esporádicos. Outras vezes, mesmo que citem procedimentos ativos que considerem a importância do trabalho cooperativo, da gestão participativa e construção coletiva de regras, muitas das práticas pedagógicas não concretizam a vivência efetiva desses procedimentos. Embora se encontrem docentes bem intencionados com propostas bem elaboradas, poucas escolas estão preparadas e efetivamente comprometidas com a reorientação de valores, de modo a contribuir para a formação da identidade moral e ética de seus alunos.
\end{abstract}

Outra forma negativa no trato com a indisciplina escolar é a transferência do problema educacional para outras esferas e profissionais que não estão diretamente envolvidos com a instituição escolar, como notamos em Brito e Santos (2009) que na questão da violência propõem apoio de outros profissionais para tentar solucionar o problema.

Encontramos isso também nas escolas na questão indisciplinar, ou seja, é recorrente o discurso de que o professor não consegue resolver sozinho o problema da indisciplina. Os professores relatam que precisam de apoio de outros profissionais, mediadores, psicólogos, psiquiatras, médicos, precisam também de uma formação específica para lidar com a temática. Constatamos em diversas entrevistas essa visão dos profissionais:

(ENTREVISTA COM O PROFESSOR DE EF - ESCOLA B): [...] O que eu percebi, é que a gente tem mesmo assim uma deficiência nessa questão da parte psicológica, de formação, quanto ao lidar com a indisciplina, [...] mas para falar sobre essa questão da formação da personalidade, para gente saber quais as sanções, o que fazer, como proceder com os alunos, para que a gente não perca o aluno no sentido de ele perder o respeito por nós, seja em uma discussão, alguma coisa. E também a gente possa ajudar para que ele possa crescer e se desenvolver. (ENTREVISTA COM A DIREÇÃO ESCOLAR - ESCOLA B): [...] a escola pública, ela é uma escola muito diversa. $\mathrm{E}$ a gente tem uma escassez de recursos humanos, então hoje eu posso dizer que nós temos assim bastante recursos pedagógicos, materiais e falta para nós o recurso humano, então isso faz diferença, então precisaríamos hoje ter psicólogo na escola, isso ia ajudar muito, [...] e nós temos muitos alunos que precisariam de uma orientação mais específica, se tivesse um psicólogo na escola, isso ia ajudar muito, ou até mesmo um psicopedagogo [...]

Como ressaltado por Alves (2002), é frequente essa transferência das causas e resoluções dos problemas que muitos educadores fazem para outras instâncias. Nas causas é reiterado por diversas vezes, como já mencionado, a culpabilidade das famílias, assim como para solucionar os problemas há um encaminhamento dos alunos com atos considerados indisciplinados, para os gestores e esses por sua vez, buscam o apoio de outros profissionais, seja os educacionais, como os professores mediadores, seja em outras instâncias como justiça, psicólogos e assistentes sociais, dentre outros. 
O auxílio de outros profissionais é benéfico para dar suporte ao docente, inclusive. A questão problemática é que os educadores deveriam mediar os conflitos de indisciplina ocorridos nas escolas e não transferir a outros profissionais exacerbadamente, "terceirizando" suas responsabilidades.

\section{CONSIDERAÇÕES FINAIS}

A presente pesquisa teve como objetivo geral identificar o entendimento de professores e equipe gestora de escolas públicas de Indaiatuba - SP sobre a indisciplina escolar e a forma como lidam com ela e como objetivo específico comparar a compreensão de indisciplina dos professores de educação física e demais professores investigados.

Por ser um tema presente em todas as escolas, consideramos tal assunto de primordial importância para todos os programas didático-pedagógicos, algo que deve ser considerado, estudado e como um desafio crescente que deve ser enfrentado.

Concluímos que, com relação ao entendimento que os docentes possuem sobre indisciplina escolar, chegamos ao resultado que os professores dificilmente citaram como indisciplina as quatro formas trazidas por nós na revisão, porém na somatória do discurso encontramos que ocorrem as quatro formas de indisciplina trazidas por nós na revisão: regimentar, social, curricular e passiva de Oliveira (2015) e também aparecem essas quatro formas na somatória dos discursos docentes sobre os casos de indisciplina que aparecem em suas aulas, independentemente do componente curricular que lecionam e consequentemente tomam atitudes equivocadas em relação ao tratamento dessa temática nas escolas. Os principais atos de indisciplina citados pelos docentes foram: desrespeito às normas, atrapalhar o desenvolvimento da aula, não realização de atividades, conversas, uso de aparelhos eletrônicos, discutir com o professor e fazer algo que foge do padrão da aula.

Com relação à forma como os docentes lidam com a indisciplina escolar, obtivemos alguns exemplos sendo os principais: apresentação das regras (não uma construção conjunta), revelando uma falta da participação da comunidade escolar nas decisões das instituições educativas como a elaboração do Projeto Político Pedagógico e normas e regimentos escolares; exclusão, suspensão e advertências; a transferência do problema que ocorre na sala de aula para a direção escolar e dessa para a família e outras esferas profissionais que não estão diretamente envolvidos com a instituição escolar. Foi verificado também que há uma ausência de projetos eficazes para a amenização de problemas de indisciplina e violência escolares.

A questão da indisciplina escolar hoje em dia nos traz muitas dúvidas. Devemos salientar a importância dessa discussão e um debate rico sobre a indisciplina escolar em todas as escolas para que haja uma compreensão por parte dos protagonistas dessa instituição, para que possa haver alternativas para esse entrave pedagógico que tanto nos limita na busca de uma educação de maior qualidade e para que possamos ganhar em conhecimento, ensino e aprendizagem por parte de todos. 
É necessário que o tema seja tratado nos cursos de formação de professores, bem como nos processos de formação continuada, para que as vivências escolares e os projetos que visam a diminuição de violência e indisciplina escolares sejam bem-sucedidos, pois notamos que muitas vezes há uma boa vontade dos professores, mas faltam experiências e vivências eficazes, consequentemente falta uma compreensão por parte de toda a comunidade escolar da maneira correta de desenvolver tais projetos.

A maioria dessas experiências não promove uma verdadeira formação para a autonomia, por inúmeros motivos, como a falta de formação, projetos descontínuos, projetos intervencionistas e não preventivos.

É importante e crucial que os projetos escolares e a formação continuada sejam efetivos, permanentes, elaborados e estruturados por meio de conhecimentos científicos, apoio de grupos de estudo, universidades, e sejam realmente programas intrínsecos na cultura escolar de forma preventiva, respaldado e embasado em estudos, pesquisas, aprofundamentos teóricos e vivências positivas, como troca de experiências, debates, discussões democráticas.

\section{REFERÊNCIAS}

ALVES, Cândida Maria Santos Daltro. (In)Disciplina na Escola: cenas da Complexidade de um Cotidiano Escolar. 2002. 176 f. Dissertação (Mestrado em Educação) - UNICAMP, Campinas.

ANDRADE, Patrícia Santos de; CARDOSO, Telma Abdalla de Oliveira. Prazer e Dor na Docência: revisão bibliográfica sobre a Síndrome de Burnout. Saúde Soc. São Paulo, São Paulo, v. 21, n. 1, p.129-140, 2012.

AQUINO, Julio Groppa. A desordem na relação professor-aluno: indisciplina, moralidade e conhecimento. In: AQUINO, Julio Groppa (Org.). Indisciplina Na Escola: Alternativas Teóricas e Práticas. 14. ed. São Paulo: Summus Editorial, 1996.

CHARLOT, B. A violência na escola: como os sociólogos franceses abordam essa questão. Sociologias, Porto Alegre, ano 4, n. 8, p. 432-443, jul./dez. 2002. In: OLIVEIRA, Mariana Tavares Almeida. Conflitos entre alunos de 13 e 14 anos: causas, estratégias e finalizações. 2015. 247 f. Dissertação (Mestrado em Psicologia Educacional) UNICAMP, Campinas.

CONCEIÇÃO, Maria Cleonice da. A indisciplina em sala de aula: estudo de caso na escola municipal dr. Urbano Maria Eulálio do município de Picos - PI. 2013. 50 f. Monografia (Graduação - Curso de Pedagogia) - UFPI, Picos, 2013.

CAPIVARI, Diretoria de Ensino da Região de. Escolas Estaduais de Indaiatuba/SP. Diretoria de Ensino da Região de Capivari. Capivari: Secretaria Estadual de Educação; 2015. Disponível em: < http://decapivari.com.br/indaiatuba/> . Acesso em: 15 out. 2015. GARCIA, Joe. Indisciplina, incivilidade e cidadania na escola. ETD - Educação Temática

Digital, Campinas, v.8, n.1, p. 124-132, dez. 2006. 
julho/2017

GRIGOLON, Ana Kuasne et al. Regras escolares: o que pensam os alunos de ensino fundamental I e II. Revista Eletrônica de Psicologia e Epistemologia Genéticas, Marília, v. 5, n. 1, p.96-127, jan. 2013.

KRAWCZUN, Natália Branco Lopes; PLATT, Adreana Dulcina. Violência e indisciplina na escola: um cotejo necessário. Revista Ibero-Americana de Estudos em Educação, Araraquara: Faculdade de Ciências e Letras; Campus de Araraquara, v. 2, n. 10, p.481503, 2015.

LA TAILLE, Yves de. A indisciplina e o sentimento de vergonha. In: AQUINO, J. G. (Org.). Indisciplina Na Escola: Alternativas Teóricas e Práticas. 14. ed. São Paulo: Summus Editorial, 1996.

MINAYO, Cecília de Souza. O desafio da pesquisa social. In: MINAYO, Cecília de Souza. (Org.); Pesquisa social: teoria, método e criatividade. 28 ed. - Petrópolis: Vozes, 2009. MINAYO, Cecília de Souza. Trabalho de campo: contexto de observação, interação e descoberta. In: MINAYO, Cecília de Souza. (Org.); Pesquisa social: teoria, método e criatividade. 28 ed. - Petrópolis: Vozes, 2009.

OLIVEIRA, Mariana Tavares Almeida. Conflitos entre alunos de 13 e 14 anos: causas, estratégias e finalizações. 2015. 247 f. Dissertação (Mestrado em Psicologia Educacional) - UNICAMP, Campinas.

REGO, Teresa Cristina R. A indisciplina e o processo educativo: uma análise na perspectiva vygotskiana. In: AQUINO, Julio Groppa (Org.). Indisciplina Na Escola: Alternativas Teóricas e Práticas. 14. ed. São Paulo: Summus Editorial, 1996.

VINHA, Telma Pileggi; TOGNETTA, Luciene Regina. A prática de regras na escola: ambiente autocrático x ambiente democrático. Educação Unisinos, São Leopoldo: Universidade do Vale do Rio dos Sinos; São Leopoldo, v. 10 n. 1 p.45-55, jan./abr. 2006.

ZECHI, Juliana Aparecida Matias. Educação em valores: solução para a violência e a indisciplina na escola? 2014. 280 f. Tese (Doutorado em Educação) - UNESP, Presidente Prudente.

Recebido em: setembro/2016

Aprovado em: maio/2017 